Ferguson, F. \& Theodore, P. (1952) Colchicine. 1. General pharmacology, Journal of Pharmacology and Experimental Therapeutics, 106, 261.

Layani, F., AsChKenasy, A. \& Mouzon, M.(1947) Intoxication aigue par la colchicine-Importantes alterations de la leucopoiese. Bulletin et Memoires de la Société médicale des hopitaux de Paris, 63, 10.

Macleov, J.G. \& Phillips, L. (1947) Hypersensitivity to colchicine. Annals of the Rheumatic Diseases, 6, 224.

MAJOR, G.W. (1874) Series of cases of poisoning by Vinum colchici recently occurring in Montreal. Canada Medical and Surgical Journal, 2, 241.

Prescott, A. \& Webster, R. (1923) In: Legal Medicine and Toxicology (Ed. by F. Peterson, W. Haines and R Web- ster), 2nd edn., vol. 2, p. 478. Saunders, Philadelphia and London.

Santavy, F., Lang, B. \& Malinsky, J. (1950) L'action mitotique et la toxicité des nouvelles substances isolées due Colchique (Colchicum autumnale L.). Archives internationales de Pharmacodynamie et de Therapie, 84, 257.

WalaszeK, E.J., Kocsis, J.J., LeROY, G.V. \& Geiling, E.M.K. (1960) Studies on the excretion of radio-active colchicine. Archives internationales de Pharmacodynamie et de Therapie, 125, 371.

Wildman, W.C. (1960) In: The Alkaloids (Ed. by R. H. F. Manske), vol. 6, p. 247. Academic Press, New York and London.

\title{
Tension pneumoperitoneum as a postoperative complication of multiple abdominal injuries
}

\author{
D. KEOWN* \\ F.R.C.S.
}

K. CRONIN
M.S., F.R.C.S.

Northampton General Hospital
TENSION pneumoperitoneum as the presenting sign of a perforated viscus is very rare (Singer, 1932; Addison, 1959) and is even more uncommon as a postoperative complication (Millar, 1962; Hughes, Cuthbertson \& Buntine, 1964). A unique case of tension pneumoperitoneum presenting in the postoperative period but not directly related to the original operation is presented.

\section{Case report}

A 9-year-old boy was admitted on 29 August 1969, after a crushing injury of his abdomen. He was moderately shocked and tender on the left side of his abdomen and flank. X-ray of the chest (Fig. 1) showed a large gas bubble filling the left pleural cavity. A provisional diagnosis of a ruptured left diaphragm was made.

At laparotomy (K.C.) the injuries were as follows:

1. There was a $10 \mathrm{~cm}$ tear on the lateral side of the left diaphragm. The stomach and spleen had herniated into the chest but were intact. The diaphragm was repaired with continuous linen thread sutures.

2. The small bowel was torn across $7.5 \mathrm{~cm}$ from the duodeno-jejunal junction. The proximal $15 \mathrm{~cm}$ of the distal part were devascularized. This part was resected and the two ends anastomosed.

* Now Consultant Surgeon, S.E. Kent Group of Hospitals.

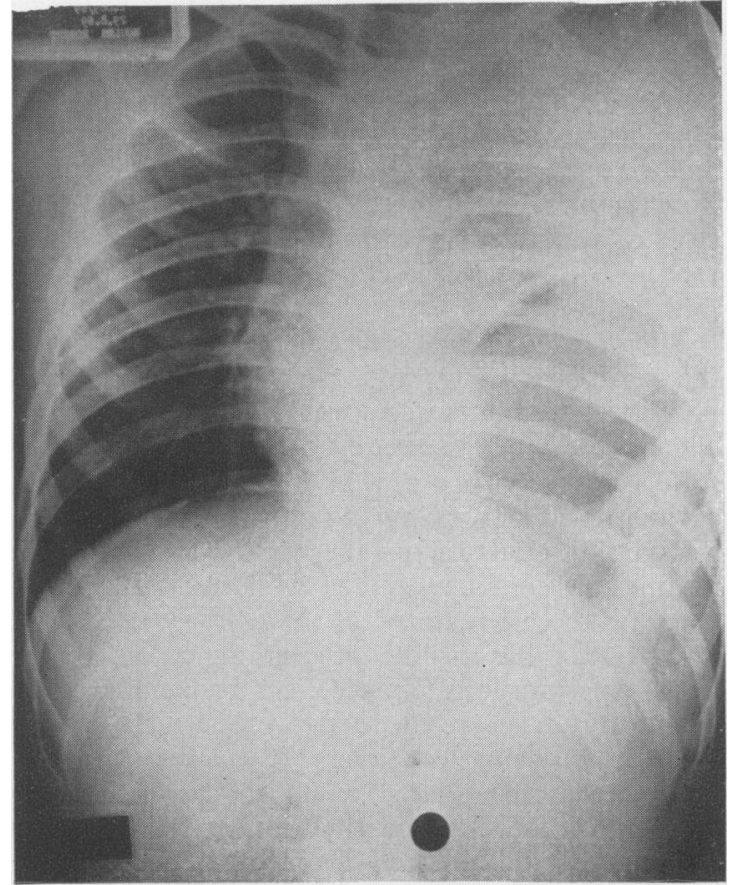

Fig. 1. Radiograph on admission showing stomach lying in left pleural cavity. 
3. The mesocolon had been torn from $7 \cdot 5 \mathrm{~cm}$ of the centre of the transverse colon and there was free venous bleeding from the root of the mesocolon. The middle colic artery was intact and the colon looked a normal colour. The portion devoid of mesocolon was exteriorized through a separate stab incision but the bowel was not opened.

The remaining abdominal viscera including the left kidney appeared to be intact.

The initial period of recovery was uneventful apart from one episode of haematuria on the night of admission. The exteriorized colon appeared to be healthy and was returned to the abdomen on the fifth postoperative day. Three days later the patient complained of colicky abdominal pains and the abdomen was found to be distended.

Bowel sounds were very active and a clinical diagnosis of a mild mechanical obstruction was made. A lateral X-ray of the abdomen, however, showed a large amount of free gas in the peritoneal cavity. Intravenous fluids were restarted and a nasogastric tube passed, but over the following week only minimal quantities were aspirated. The abdomen became increasingly distended and by the twelfth postoperative day a huge pneumoperitoneum had developed (Fig. 2). The boy's condition remained remarkably good and conservative treatment was continued on the basis of low gastric aspirates, the presence of bowel sounds and the passage of flatus. By the sixteenth postoperative day the pneumoperitoneum was increasingly interfering with breathing and the intra-abdominal pressure was $30 \mathrm{~mm}$ Hg. The air was let out using a trochar and cannula and the abdomen rapidly deflated. The child's condition improved temporarily but he then developed signs of a spreading peritonitis and a further laparotomy (D.K) was therefore carried out on the nineteenth day.

There was a considerable quantity of clear fluid in the peritoneal cavity and the whole of the small bowel was found matted together by thin adhesions which were easily separated. A small collection of soft faeces was found lying free in the peritoneal cavity immediately below the transverse colon which was grossly dilated from the hepatic to the splenic flexure and completely filled with soft faeces. The diameter of this segment of the colon was at least three times that of the descending colon. Three minute perforations about $5 \mathrm{~cm}$ proximal to the previously exteriorized loop were clearly visible with faeces oozing from them. It was impossible to bring the atonic dilated colon to the surface on account of the extreme thinness of its wall and accordingly the affected segment of colon was excised with considerable difficulty. The transverse mesocolon was grossly thickened but the middle colic artery bled briskly when it was divided. The proxi-

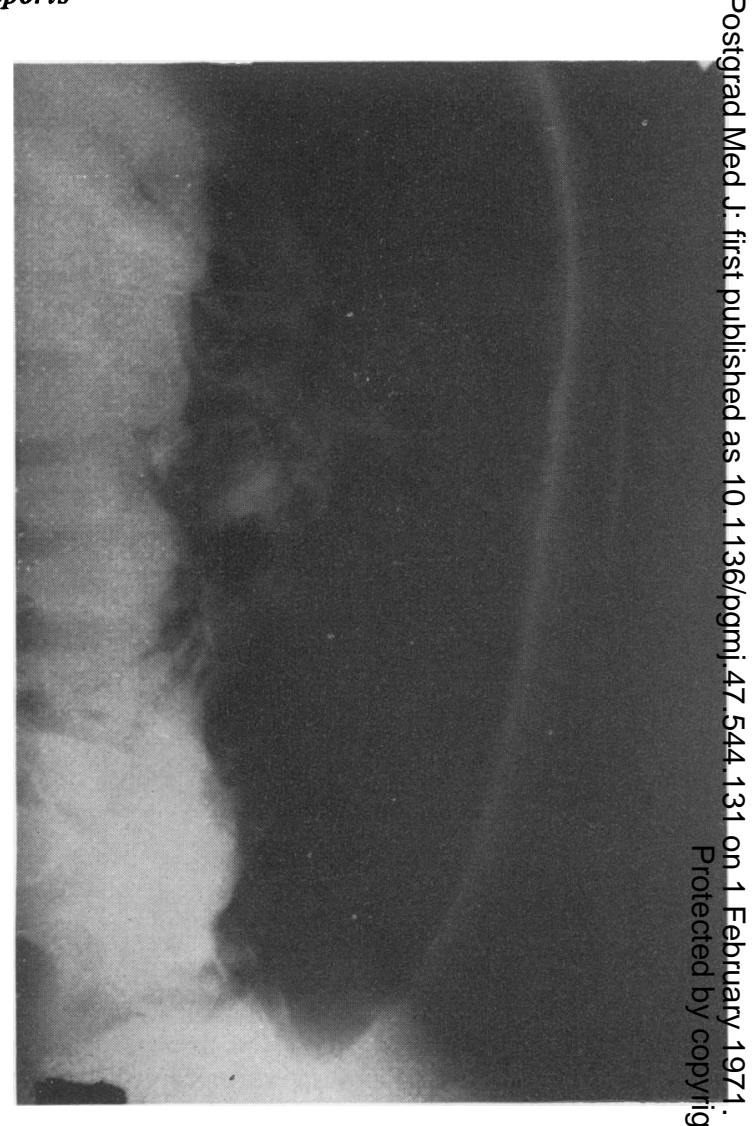

Fig. 2. Lateral X-ray of abdomen showing a large amount of free gas in the peritoneal cavity.

mal end of the remaining colon was exteriorizedڤ through the upper end of the paramedian incision® and the distal end through a stab incision in the left $\overrightarrow{\vec{F}}$ flank. A peculiarly watery thickening of the muscles 3 of the posterior abdominal wall underlying the splenic flexure was noted but no particular significance was attached to it. A large corrugated plastic drain was left down to this area. Fig. 3 shows the resected specimen of colon measuring $30 \mathrm{~cm}$ long.

The child withstood the operation well. The fol lowing day there was a copious discharge of wateryo fluid from the abdominal drain and analysis of the fluid showed it to be urine. The quantity collectedo daily initially equalled the urinary output from the bladder. The urinary fistula persisted unabated for 2 weeks but thereafter the volume gradually dimi- $\tilde{N}$ nished. The child's general recovery was very slow and included a phase of negativism and refusal to $\tilde{S}$ eat. He was allowed home 69 days after the accident ${ }_{\omega}^{N}$ and thereafter made good progress. He was seen in the Out-patient Department in February 1970; theo urinary fistula had healed completely. An intra- $\frac{\mathbb{\Phi}}{\infty}$ venous pyelogram showed a functioning left kidney 


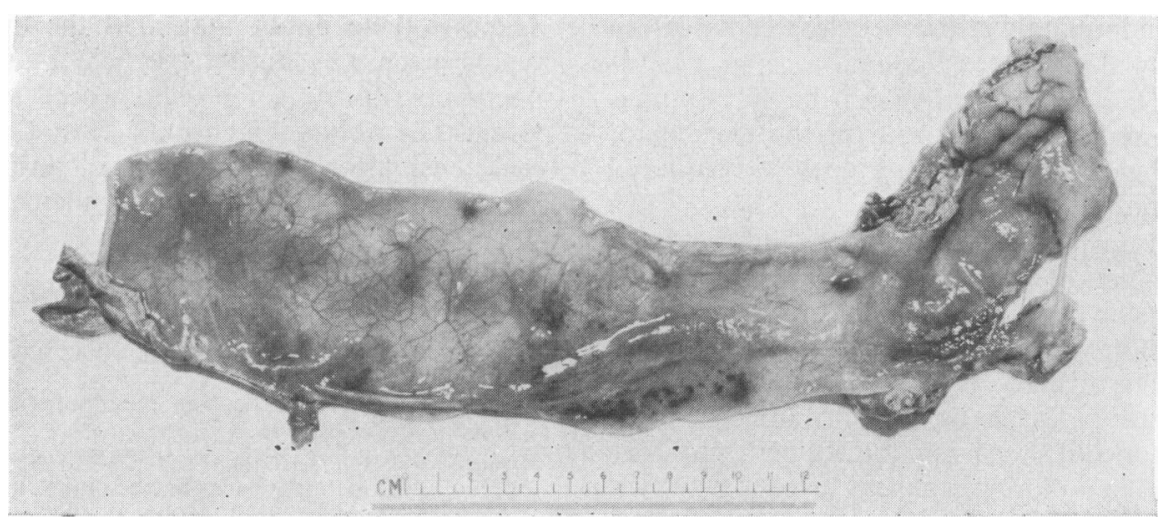

FIG. 3. Resected segment of colon showing atrophy and thinning of the central portion.

with some hydronephrotic changes. It is intended to restore continuity of the large bowel at a later date.

\section{Discussion}

Hughes et al. (1964) report three cases of postoperative tension pneumoperitoneum. Their sole survivor was subjected to laparotomy within $48 \mathrm{hr}$ of the onset of the pneumoperitoneum. One case treated by paracentesis and another by delayed laparotomy 15 days after the onset of the pneumoperitoneum both died. They conclude 'Laparotomy and drainage should be performed promptly. Abdominal paracentesis may allow faeces to escape into the peritoneal cavity once the restraining pressure has been removed'. Millar (1962), however, reports one case of postoperative tension pneumoperitoneum treated by paracentesis with complete recovery. It is, however, only fair to state that the cases reported by Hughes et al. had all undergone colonic resection and anastomosis whereas Millar's case followed removal of a non-perforated but inflamed appendix.

Review of the case presented here shows that no hard and fast rules can be laid down and the management should be determined by the clinical picture in conjunction with an attempt to assess the underlying pathological process. The pathological progression of the colonic lesion here can be seen only in retrospect. Histological examination of the central part of the removed colon showed complete disruption of the muscular layers of the colon. The pathologist is quite certain that this disruption was not an artefact from the preparation of the specimen. Such a disruption is easily understood on considering the forces involved in the injury and the damage to the adjacent viscera. As the child was progressively crushed the elastic rib cage was lengthened laterally with rupture of the diaphragm and eventration of the stomach and spleen thereby saving these organs from almost certain rupture. The partly fixed transverse colon would then be subject to considerable compression resulting in rupture of the thin walled veins before the compressing forces were finally spent on the posterior abdominal wall. Disruption of the muscle wall of the colon can be easily visualized under these circumstances. It is postulated that this muscular disruption combined with possible venous insufficiency were the chief factors producing the final operative picture of an inert paper-thin colon. The exteriorized colon initially appeared quite healthy because of an intact arterial supply combined with the absence of faeces within its lumen. Once motor activity returned to the bowel dilatation of this disrupted inert segment of colon began because of its inability to propel its contents distally. Absorption of water in the presence of an initially intact circulation would lead to inspissation of the colonic contents and allow further entrance of more faeces from the proximal colon leading to further dilatation of the colon and interference with an already partially inadequate circulation. A vicious circle would thus arise culminating in perforation of the colon at the point of maximum pressure or greatest vascular deficiency. This process may well have begun in the colon proximal to the exteriorized loop, the distal colon being protected by the spur formed by the glass rod from the transmitted pressure of the healthy colon. This would explain the site of the perforations being proximal to the exteriorized loop.

On the whole we agree with Hughes' dictum that prompt laparotomy is essential particularly when paracentesis has released the restraining pressure. However, in the case under review here earlier laparotomy might have resulted in failure to appreciate the extent of the disrupted colon with consequent inadequate excision. The period of conservative treatment following the onset of postoperative 
distension undoubtedly allowed a clear demarcation between normal and dilated colon.

The presence of tenderness in the left lumbar region followed by haematuria on the evening of admission suggests that the left kidney was ruptured by the original injury.

The intact posterior parietal peritoneum provided good splintage for the injured kidney until the nineteenth day when this barrier had to be disrupted when the colon was excised. This was probably the reason why a urinary fistula appeared after the second operation. Earlier laparotomy and disruption of the peritoneum overlying the kidney may well have resulted in a more permanent urinary fistula by interfering with the healing process at a more crucial stage.

It is also felt worthwhile to stress the value of unabsorbable sutures in the repair of the diaphragm.
There is little doubt that, had the diaphragmatico repair given way during the height of the tension pneumoperitoneum, the child would not have sur vived. The ability of chromic catgut to withstand such tension for such a prolonged period late in the postoperative phase is highly problematical.

\section{Acknowledgment}

We thank Mr G. B. Dun for the illustrations.

\section{References}

Addison, N.V. (1959) Tension pneumoperitoneum. British Journal of Surgery, 46, 411.

Hughes, E.S.R., Cuthbertson, A.M. \& Buntine, J.A $\overrightarrow{0}$ (1964) Postoperative tension pneumoperitoneum. British Journal of Surgery, 51, 174.

MillaR, D.M. (1962) Tension pneumoperitoneum: A post operative complication. British Journal of Surgery, 49, 3940

SiNGER, H.A. (1932) Valvular pneumoperitoneum. Journal of the American Medical Association, 99, 2177.

\section{Hypoglycaemic coma after partial gastrectomy}

\author{
P. A. BACON* \\ M.B., M.R.C.P.
}

\author{
A. B. MYLES $\dagger$ \\ M.B., M.R.C.P.
}

